\title{
Factors Influencing Student STEM Career Choices: Gender Differences
}

\author{
Tandra Tyler-Wood ${ }^{\mathrm{a}}$, Karen Johnson ${ }^{\mathrm{a}}$, Deborah Cockerham ${ }^{\mathrm{b}}$ \\ ${ }^{a}$ University of North Texas, USA; ${ }^{b}$ Fort Worth Museum of Science and History, USA
}

\begin{abstract}
This study examined factors that influence middle school students' dispositions towards science, technology, engineering, and math (STEM) careers. Interest and ability in STEM subject areas were compared by gender, based on 182 middle school students' responses to four different test instruments. While findings from $t$-tests indicated significant differences between males and females on mathematics interest scores, no significant differences were found in science, technology, engineering, or STEM career interest. Stepwise multiple regression showed that STEM variables explained 47\% of the variance in boys pursuing a STEM career and 36\% of the variance in girls. The findings of this study underscore the challenges that still exist in achieving equal gender representation in the STEM workforce, and suggest that adopting a constructivist learning approach may provide a foundation for girls to develop a more positive approach toward science, boost STEM awareness and interest, and increase STEM success.
\end{abstract}

Keywords: Constructivism, STEM education, STEM careers, gender gap

\section{Introduction}

The fields of science, technology, engineering, and mathematics (STEM) are critical to national and global competitiveness in the technologically-driven economy. These disciplines have been designated as high priority educational areas by the National Education Agency and other federal agencies (Goan \& Cunningham, 2006). Increased need for STEM professionals is driven by factors such as real and immediate economic and societal needs (Connors-Kellgren, Parker, Blustein, \& Barnett, 2016): retirement of baby boomers, projected STEM job opportunities (Mau, Perkins, \& Mau, 2016), national and strategic significance, the need for a homegrown STEM workforce, and the equity and value of a diverse workforce (Connors-Kellgren, et al., 2016). Work in the STEM fields drives innovation and has an immense impact on competitiveness, economic growth, and the overall standard of living (U.S. Economics and Statistics Administration, 2017).

In response to the need for a qualified workforce, the U.S. has invested in STEM education (Wang \& Degol, 2013) through agencies such as the U.S. Department of Education and the National Science Foundation (NSF), which both support extensive research and education in STEM programs (ConnorsKellgren et al., 2016). Policy maker and employer investment in STEM education has often been motivated by evidence of the macroeconomic benefits of preparing students for STEM careers (Connors-Kellgren et al., 2016).

Over the past ten years, employment has increased much faster in STEM occupations (24.4\%) than in non-STEM occupations (4.0\%). Opportunities in the STEM professions are projected to grow by $8.9 \%$ between 2014 and 2024. In 2015, 9 million STEM workers were employed in the U.S. (U.S. Economics and Statistics ${ }^{1}$ Corresponding author. UNT Departmant of Learning Technologies, Discovery Park, G155 E-mail: tandra.wood@unt.edu Tyler-Wood, T., Johnson, K., \& Cockerhan, D. (2018). Factors Influencing Student STEM Career Choices: Gender Differences. Journal of Research in STEM Education, 4(2), 179-192. 
Administration, 2017). However, the need to meet the demands of the labor market has spurred significant concerns about a future deficit of STEM workers (Jackson, Charleston, Lewis, Gilbert, \& Parrish, 2017; US Bureau of Labor Statistics, 2015; Wang \& Degol, 2013).

While recent research indicates that the numbers of STEM graduates are increasing (Salzman, 2013), male students continue to strongly outnumber females in some STEM fields of study (Jackson, et al., 2017; Kanny, Sax, \& Riggers-Piehl, 2014). Although recent research suggests a narrowing of gender differences in fields such as biology (Kanny et al., 2014), females are generally underrepresented in STEM programs, especially in engineering, computer science (Kanny et al., 2014; Sax, 2012; Jacobs, 1996), and math (Salzman, 2013; Wang \& Degol, 2017). Furthermore, the National Center for Education Statistics (Aud et al., 2012) indicates that the percentage of women receiving bachelor's degrees in engineering has increased only slightly (14\% to $17 \%)$ over the past 25 years, and the number of women receiving bachelor's degrees in computer science has significantly declined (36\% to $18 \%)$.

Current studies suggest paradoxical findings: although STEM professionals are predominantly male, girls generally achieve higher grades in mathematics than boys. Higher grades indicate ability for success in mathematics studies, a strong precursor of success in STEM careers. (Stoeger, Duan, Schirner, Greindl, \& Ziegler, 2013; Wang, Degol, \& Fe, 2015). Despite the vast body of research that attempts to explain both the gender gap in STEM programs and the continued deficit of females in STEM course enrollment, female involvement in certain STEM fields has remained consistent (Wang \& Degol, 2013). Because the reasons for the gap may have changed through the years (Kanny, et al., 2014), an understanding of factors that influence girls' educational and career choices and motivations that may encourage female interest in STEM careers is critical. Academic and affective predictors for STEM career choices as early as elementary and middle school education must be examined (Kanny et al., 2014).

The purpose of this study is to investigate factors that may influence middle school students' career preferences. The primary question is: Are 7th grade male and female student attitudes towards a STEM career influenced by similar factors? Student spatial skills, ability and performance levels, and interest in STEM subjects will be examined.

\section{Theoretical Framework}

Human constructivist learning is used in this study as a theoretical lens to explain factors that influence middle school students' attitudes, interests, and performance in STEM education and STEM career choices. Human constructivist learning offers a philosophical view about how humans learn (Ultanir, 2012) and significantly influences the modern education system. Success in the twenty-first century requires teaching strategies that allow students to make meaning and build knowledge (Mintzes, Wandersee, \& Novak, 2005). Constructivist theory emphasizes the meaning-making capacity of the human mind and is based on an understanding of how knowledge is constructed and how humans learn (Mintzes et al; Ultanir, 2012). Constructivism focuses on the recognition that learning requires active cognitive engagement (Bretz, 2001), and focuses on active, student-directed learning (Yager, 1991, p. 53). In this model, learning is not dependent upon teacher presentations, but takes place as the student assimilates new information into his previous knowledge and perceived notions (Yager, 1991).

In the past, the behaviorist approach to teaching and learning dominated U.S. pedagogy (Yager, 1991), but this approach does not support deep understanding or development of skills required for synthesis and transfer (Yager, 1991). Deep understanding is constructed from learner experience, knowledge, ideas, and activities (Ultanir, 2012), and is supported as students learn words, sentences, and stories to make sense of the environment and communicate concepts (Yager, 1991).

The teacher who utilizes a constructivist approach serves as a guide, encouraging the learner to question, challenge, and formulate his own ideas, opinions, and conclusions (Ultanir, 2012). Learning is extended beyond the classroom so that students view science as more than something that merely exists to be mastered on tests 
(Yager, 1991). Adopting the constructivist approach to teaching may help to reduce the gender gap in STEM education. A constructivist approach may provide a foundation upon which females develop a more positive approach toward science, boost STEM awareness and interest, and increase STEM success.

\section{Literature Review}

Women's underrepresentation in STEM careers has been rigorously researched over the past 25 years (Kanny et al., 2014). While some studies (Cheryan, et al., 2017) suggest that gender differences in STEM interest usually appear before college, others (Freeman, 2004, cited in Tyler-Wood, Ellison, Lim, \& Periathiruvadi, 2011) suggest that STEM achievement does not show significant gender differences. In order to capture major factors influencing the gender disparity, our studybegan with a review of two meta-analyses. Blickenstaff (2005) analyzed literature on the gender gap from 1970 through 1991, and proposed nine contributing factors of women's underrepresentation in STEM: 1) biological differences, 2) academic preparation, 3) attitude toward STEM, 4) a lack of role models, 5) curriculum, 6) pedagogy, 7) "chilly" climate in STEM classes, 8) genderrole socialization, and 9) epistemological differences. More recently, Kanny et al. (2014) investigated research addressing the evolvement of scholarship on the STEM gender gap over four decades (1970 to 2010). This study is inclusive of more current studies and represents a value-added follow up to Blickenstaff's (2005) research. Based on a systematic review of 324 peer-reviewed texts, the study identified patterns and themes in five dominant narrative explanations: 1) individual background characteristics, 2) structural barriers in K-12 education, 3) psychological factors, values, and preferences, 4) family influences and expectations, and 5) perceptions of STEM fields. Some of these phenomena affect children as early as age 4 and continue to affect attitudes, interests, perceptions of, and experiences in STEM throughout K-12 education. Despite evidence that many efforts have been made to address the gender gap, the discrepancy persists (Wang \& Degol, 2013). Reasons for the gap may have changed, but these remain unclear (Kanny et al., 2014).

\section{Women in STEM Careers}

Some STEM fields are relatively gender-balanced, while others are largely ignored by women. For example, women receive more than half of the U.S. undergraduate degrees in biology, chemistry, and mathematics, but less than $20 \%$ of computer science, engineering, and physics undergraduate degrees (National Science Foundation, 2014). Although years of extensive research on the gender gap issue has been conducted in a wide cross section of disciplines, the extant literature is limited (Wang, Degol, \& Ye, 2015). Many of these studies view the college major as the primary determinant for outcome and STEM performance and career choice (Lubinski \& Benbow, 2006), but multiple factors have already come into play by the time a student is in college (Tyson, 2011). Other efforts focus on increasing student exposure and performance in high school math courses (Eccles, 2009), but evidence that career aspirations are formulated in the earlier years suggests that investigations should begin in the first educational encounters.

Signs of the gender gap surface as early as elementary school, with males and females exhibiting comparable STEM performance, but less interest in STEM among girls than boys (Unfried, Faber, \& Wiebe, 2014). Currently, most literature still seeks to understand ways to increase the number of women who pursue and persist in STEM (Cheryan, Ziegler, Montoya, \& Jiang, 2017), but little evidence to date indicates specific factors that explain women's underrepresentation in some STEM fields (Cheryan et al., 2016). In order to unearth some of the contributing reasons for the gap from an early age, our research focused on seventh grade students' dispositions towards STEM careers. More specifically, we examined boys' and girls' interests in STEM and/or STEM careers as well as STEM-related subject/content areas required to develop skill sets needed to pursue STEM education. The content areas investigated are spatial reasoning skills and visual perception (Shapes Test), general thinking processes in science and mathematics (Trends in International Mathematics and Science), and scientific understanding involved in construction of a solenoid. 


\section{Attitude and Preference Toward STEM}

Attitude and preference may play large roles in gender disparity for STEM interest and career choice. A 1995 meta-analysis of studies conducted between 1970 and 1991 (Weinburgh, 1995) suggested that males' attitudes towards science are generally more positive than are females' attitudes, and that attitude towards science underscores STEM achievement. An observational study of interactions at a children's science museum found that parents tend to spend more time explaining scientific exhibits to boys than to girls (Crowley, Callanan, Tenenbaum, \& Allen, 2001). With this parental guidance, boys will more naturally develop a positive inclination for STEM. Similar experiences have likely influenced gender gaps in college students' goals (Dabney \& Tai, 2014).

A meta-analysis of 47 career interest inventories, looking at scores of over 500,000 participants ( $\mathrm{Su}$, Rounds, \& Armstrong, 2009) suggested that career preference may vary markedly by gender. Results indicated that, in general, men prefer working with things, while women prefer working with people. However, authors cautioned that the wording of questions on specific inventories may skew the results, and advised vocational counselors to consider this fact in selecting instrumentation. An action research study (Tyler-Wood, Ellison, Lim, \& Periathiruvadi, 2011) explored the development of positive attitudes among females. In this study, 34 fourth and fifth grade girls were paired with female high school science mentors, and engaged in outdoor, "hands-on" science experiences. Results showed that most of the participants increased in scientific awareness and confidence. Therefore, adopting a constructivist approach could increase the likelihood of attitude and preference toward STEM across genders.

\section{Gender Differences in STEM Ability, Performance, and Career Interest}

Multiple studies investigating gender differences in math performance suggest comparable math ability, but slightly stronger female performance (Lindberg, Hyde, Petersen, \& Linn, 2010; Voyer \& Voyer, 2014, cited in Diekman, Steinberg, Brown, Belander, \& Clark, 2017). A 2007 study examining subskills involved in both math and science found that, while females are generally more proficient in writing and other essential STEM communication skills, males have a stronger understanding of abstract ideas (Halpern et al., 2007). Authors attributed these gender differences to a combination of early experience, biological factors, educational policy, and cultural context, and found similar ability results for both males and females.

Since ability levels appear to be similar for boys and girls, Diekman et al. (2017) suggest a communal goal congruity model to motivate students to choose STEM careers. This model explores the impact of community goals upon decisions to pursue STEM careers, with communal goals defined as those that provide the opportunity to be with or to help others. Girls often gravitate more towards the communal expectations, which are not traditionally perceived as STEM careers. Perceptions of expected social roles appear to begin in early childhood, and are important components of self-perception and motivation (Cross \& Madsen, 1997). If girls are made aware of the importance of socially oriented STEM jobs through human constructivist learning, their interest in STEM careers may extend into areas that are currently underrepresented by females.

\section{Gender Differences in Spatial Ability}

Studies involving spatial ability (Jeng \& Chen, 2013; Hedman et al., 2006, Ceci \& Williams, 2007) show the importance of spatial subskills for learning STEM concepts. Spatial ability is multi-faceted, and individual studies have shown discrepancies in identifying and labeling its various components. While Stumpf and Eliot (1995) identified subskills such as mental rotation, visual memory, and a strong "general factor", a meta-analysis of 172 empirical studies (Linn \& Peterson, 1985) defined key factors as spatial perception, spatial visualization, and mental rotation.

In spatial perception tests, each participant must examine spatial relationships between the object or picture and the orientation of his own body. Spatial visualization describes the ability to mentally rotate whole or partial 3D objects in space. In a study that investigated the involvement of spatial visualization and logical 
reasoning skills in high school geometry achievement, Battista (1990) found that males were significantly stronger than females in spatial visualization. Whereas males tended to use spatial visualization for problem solving, females used verbal skills and logical reasoning. Problem solving scores between genders were comparable.

Mental rotation, which involves the ability to mentally rotate 2D or 3D objects (Linn \& Peterson, 1985) has been implicated as a key factor in gender differences. In a study that investigated elementary students' developmental and gender differences, Jeng \& Liu (2013) found interesting variations. Performance on mental rotation tasks was stronger for fourth and fifth grade females than for age-matched males. However, by sixth grade, the gender gap had grown, and male performance had moved beyond that of females. Authors, noting that fifth grade (around age 10) appeared to be a critical time for building spatial skills, attributed this change to the more abstract and application-based instructional approach to sixth grade spatial concepts. They asserted that "mental rotation" tasks became "spatial visualization" tasks in sixth grade, and concluded that more direct instruction in concept application could narrow the gender gap. A study by Stumpf and Eliot (1994) further revealed this trend, with middle and high school males outperforming females on mental rotation, but females excelling in visual memory tasks.

The purpose of the current study is to investigate factors that influence middle school students' career choices. More specifically, the study aims to investigate the spatial skills, ability and performance levels, and interest of middle school students in subject areas that will create a direct pathway to STEM programs and ultimately STEM careers. The overarching research question guiding this study is: factors?

Are 7th grade male and female student dispositions towards a STEM career influenced by similar

Sub-questions to be investigated are:

1. Do 7th grade male and female test scores differ in variables related to STEM?

2. Do these factors predict a best fit model for 7 th grade male and female attitudes towards a career in STEM?

Test scores will help to determine boys' and girls' attitudes and abilities toward STEM in each of the following areas:

1. Science, technology, engineering, math, and/or STEM career (STEM Semantic Survey)

2. Knowledge of STEM (TIMSS)

3. Visual perception (SHAPES test)

4. Knowledge of solenoid (Solenoid Test)

This study aims to broaden the understanding of factors influencing STEM career choices and to guide future gender gap STEM research.

\section{Research Method}

Since factors that influence gender decision toward STEM education and career are still being investigated, an exploratory research approach was utilized for this study. While exploratory research does not offer conclusive evidence for the existing problem, this approachexplores the problem with varying levels of depth, leading to new insights and better understanding (Singh, 2007). Although causal factors influencing the gap have been suggested, questions concerning the reasons for female underrepresentation in STEM still abound. 


\section{Research Context and Samples}

Seventh graders $(\mathrm{N}=182)$ in two Title I rural Texas school districts participated in this study, which was part of a large NSF project (NSF1510289). The two school districts were chosen based on access and their similarities in demographics. Only pre-intervention data that were gathered prior to the initiation of the sponsored study were assessed; no post intervention data from the sponsored study was included in this analysis. The actual number of students completing each assessment varied, since some student surveys were incomplete and other students were absent when specific surveys were given. Table 1 lists number of respondents by survey. Data was not used for students who did not complete a survey or who were absent when a survey was taken. Students with missing data critical to an analysis were removed from the data set for that analysis.

Table 1.

T-test Comparing Means of 7th Grade Girls and Boys on STEM Variables

\begin{tabular}{|c|c|c|c|c|c|}
\hline & Gender & $\mathrm{N}$ & Mean & SD & Sig \\
\hline \multirow[t]{2}{*}{ Science Subtest ${ }^{*}$} & Male & 88 & 13.92 & 5.38 & .22 \\
\hline & Female & 87 & 15.03 & 6.68 & \\
\hline \multirow[t]{2}{*}{ Technology Subtest* } & Male & 88 & 10.13 & 5.62 & .83 \\
\hline & Female & 87 & 10.30 & 5.10 & \\
\hline \multirow[t]{2}{*}{ Engineering Subtest* } & Male & 88 & 12.20 & 7.50 & .26 \\
\hline & Female & 87 & 13.45 & 7.17 & \\
\hline \multirow[t]{2}{*}{ Mathematics Subtest* } & Male & 88 & 17.25 & 7.80 & .05 \\
\hline & Female & 87 & 19.84 & 9.47 & \\
\hline \multirow{2}{*}{$\begin{array}{l}\text { STEM Career } \\
\text { Interests }\end{array}$} & Male & 88 & 15.14 & 6.55 & .62 \\
\hline & Female & 87 & 15.35 & 6.43 & \\
\hline \multirow[t]{2}{*}{ Solenoid } & Male & 84 & 3.75 & 1.77 & .17 \\
\hline & Female & 86 & 4.09 & 1.48 & \\
\hline \multirow[t]{2}{*}{ TIMSS } & Male & 84 & 3.96 & 1.83 & .93 \\
\hline & Female & 84 & 3.94 & 1.50 & \\
\hline \multirow[t]{2}{*}{ Shapes } & Male & 84 & 17.99 & 2.08 & .97 \\
\hline & Female & 82 & 18.00 & 2.25 & \\
\hline
\end{tabular}

${ }^{*}=$ reversed scale, low numbers equal higher affinity towards subject area.

School I is a middle school that houses around 400 seventh and eighth grade students. Roughly $70 \%$ of students are ethnically white, $23 \%$ are Hispanic, and 3\% are African Americans. The remaining students are Native American, Asian, or biracial. This campus has an economically disadvantaged population of 45\%. School 2 is a middle school with a population of 220 students in grades seven and eight. The ethnic distribution of this campus includes 61\% white, 31\% Hispanic, 2\% African American, and 6\% Native American, Asian, or biracial. The population of economically disadvantaged students at School 2 is $64 \%$ of the total. Student surveys were administered by the school technology directors, and were completed online through Survey Monkey.

\section{Instrumentation}

During the spring of the 2016-2017 academic year, students in both schools were tested with the following instruments: STEM Semantic Survey (subtests: affinity towards science, technology, engineering, mathematics, and career in STEM), Trends in International Mathematics and Science Study (TIMSS) Limited 
Administration, Shapes Test, and Understanding a Solenoid. Demographic data were also collected.

STEM Semantics Survey. The STEM Semantics Survey (Tyler-Wood, Knezek, \& Christensen, 2010) was used to measure students' interest in science, technology, engineering and mathematics as well as interest in STEM careers. The survey is comprised of five scales, each with five items measured on a 7-point scale. The scores that are obtained when the instrument is scored are an inverted scale where a score of one indicates a very high affinity toward the STEM item and a seven indicates a very poor affinity towards the item. In the original study (Tyler-Wood, Knezek, \& Christensen, 2010), reliability estimates ranged from 0.84 to 0.93 , which are considered to be "very good" to "excellent" (DeVellis \& Dancer, 1991) (See Appendix 1). Internal consistency ratings for the five subscales from this data set ranged from 0.82 to 0.84 , with an overall rating of "very good" (DeVellis \& Dancer, 1991). The instrument lists adequate content and construct validity (TylerWood, Knezek, and Christensen, 2010).

TIMSS Limited Assessment. The TIMSS assessment used in the current study (Stansell \& Tyler-Wood, 2016) represents a locally developed academic test comprised of items adapted from the previously released Trends in International Mathematics and Science Study (TIMSS) questions. TIMSS math and science questions were selected based on specific content related to general thinking processes in science and math that are not content specific (Stansell \& Tyler-Wood, 2015). Schult and Sparfeldt (2016) established the concurrent validity of the TIMSS multiple choice items by comparing the math and science grades of students to their scores on the TIMSS ( $r=.5)$. This correlation indicates that the TIMSS multiple choice items have a moderate predictive value for grades. Reliability was established by comparing multiple choice and constructed response items $(\mathrm{r}=.94)$. The reported reliability of the TIMSS is high.

Shapes test. The Shapes Test (Tyler-Wood, 2015) was developed as a quick assessment for spatial reasoning skills. The Shapes Test consists of 20 questions that were produced in a grid format with the stimulus image in the far left box and the selection items to the right as shown in the sample item below (see Figure 1). While the demonstration items were presented on a reusable laminated document, the 20 test items were presented to the students on paper so that they could circle their choices.

\begin{tabular}{|c|l|l|l|l|l|}
\hline Demonstration \#1 & Circle the Participants Selection & Score $1 \quad 0$ \\
\hline
\end{tabular}

Figure 1. Shapes Test sample item. The participant marks the best match (highlighted in this example) for the first item in the row.

Zimmerman (2016) provides evidence of validity and reliability for the Shapes Test, and has compared the Shapes Test to the Cube Design section of the Universal Non-verbal Intelligence Test. A bivariate Pearson Correlation was performed to determine if the two variables were related to each other. The Pearson's coefficient obtained was .349, indicating a moderately strong correlation. Zimmerman performed a test-retest analysis to establish reliability and obtained a Pearson Correlation of .465 (moderately high).

Understanding a solenoid. The solenoid test contains six items, each scored with a Likert scale rating of 1 to 3. This assessment was developed with NSF funding and measures students' understanding of a solenoid. The test consists of multiple choice items with corresponding descriptive responses. Previous uses of the test 
have indicated that increases in test scores occur as a result of participating in the solenoid instructional unit (Rutter, Standish, \& Bull, 2016). For analysis of the assessment, a panel of experts developed a scoring rubric of descriptive responses. Content related validity was established through consensus agreement of a math professor, a science professor, a math teacher, and a doctoral student studying Curriculum and Instruction with a bachelors in engineering. Each member of the panel coded the results individually, and they convened as a group to discuss their decisions. Consensus was reached between all members on most questions, and notes of explanation were included for the few questions without consensus. Inter-rater reliability is reported at above .90 .

\section{Procedures}

Data were analyzed from an existing, large NSF data set to identify differences between 7th grade boys and girls regarding their attitudes and abilities in STEM. Independent $\mathrm{t}$-tests were run on each of the following dependent variables: STEM Semantic Survey, TIMSS limited assessment, the Shapes Test, and Understanding a Solenoid. Gender (male, female classification) served as the independent variable. An overall stepwise multiple regression was run to determine the best model for predicting 7th grade boys' and girls' interest in a STEM career. Stepwise regression is a tool that helps to identify useful predictors during the exploratory stages of model building for linear regression. It constructs a single model using the p-values of the predictor variables, and the key benefit is the simplicity of the single model. As the current study is exploring how STEM variables relate to career preference, stepwise regression was selected to evaluate whether students' affinities towards and knowledge of STEM-related subject areas (dependent variables) are necessary to predict gender (independent variable) interest in STEM careers. The analyses were conducted using SPSS version 24.0.

\section{Results}

The results of the study will be reported in two parts. First, results from t-tests will be noted to describe statistical significance between independent and dependent variables. Second, the results from stepwise multiple regression analysis will be discussed in relation to the research questions.

\section{T-test Analysis}

T-tests addressed the first research sub-question: Do 7th grade male and female scores differ in variables related to STEM? T-tests completed on the subtests of the STEM Semantic Survey indicated no significant differences between boys' and girls' scores on the following Science, Technology, Engineering, and Career Interest subtests (see Table 1):

- Science subtest: boys $(\mathrm{M}=13.92, \mathrm{SD}=5.38)$; $\operatorname{girl}(\mathrm{M}=15.03, \mathrm{SD}=6.68$; $\mathrm{t}(-1.22)=173, \mathrm{p}=.22)$

- Technology subtest: boys $(\mathrm{M}=10.13, \mathrm{SD}=5.65)$; girls $(\mathrm{M}=10.30, \mathrm{SD}=5.095) ; \mathrm{t}(-.21)=173, \mathrm{p}=.83)$

- Engineering subtest: boys ( $M=12.20, \mathrm{SD}=7.50)$; girls $(\mathrm{M}=13.45, \mathrm{SD}=7.17) ; \mathrm{t}(-1.12)=173, \mathrm{p}=.26)$

- Career interest subtest: boys $(\mathrm{M}=15.14, \mathrm{SD}=6.55)$; girls $(\mathrm{M}=15.35, \mathrm{SD}=6.43) ; \mathrm{t}(-.21)=173, \mathrm{p}=.84)$

However, on the mathematics subtest, a significant difference was seen in the scores for boys $(M=17.25$, $\mathrm{SD}=7.80)$ when compared to girls $(\mathrm{M}=19.84, \mathrm{SD}=9.47) ; \mathrm{t}(-1.97)=173, \mathrm{p}=.05)$.

An independent t-test was performed on the tests, with no significant difference seen for the following tests:

- Understanding the Solenoid test: boys ( $\mathrm{M}=3.75, \mathrm{SD}=5.38)$, girls $(\mathrm{M}=4.09, \mathrm{SD}=1.48) ; \mathrm{t}(-1.37)=168$, $\mathrm{p}=.17)$

- TIMSS test: boys $(\mathrm{M}=3.96, \mathrm{SD}=1.83)$, girls $(\mathrm{M}=3.94, \mathrm{SD}=1.50) ; \mathrm{t}(.092)=166, \mathrm{p}=.93)$

- Shapes Test: boys $(\mathrm{M}=17.99, \mathrm{SD}=2.08)$, girls $(\mathrm{M}=18.00, \mathrm{SD}=2.24) ; \mathrm{t}(-.04)=164, \mathrm{p}=.97)$ 
The above t-tests addressed the first research question: Do 7th grade male and female middle school students' scores differ in variables related to STEM? Overall, except for the mathematics subtest on the STEM Semantics Survey, no difference was found between the scores of boys and girls in relation to STEM.

\section{Stepwise Multiple Regression Analysis}

Stepwise multiple regression analyses addressed the first research sub-question: Do these factors predict a best fit model for 7th grade male and female attitudes towards a career in STEM? Stepwise multiple regression was performed to determine the capability of STEM variables for predicting career interest for girls. Three variables surfaced as a "best model" (engineering interest, math interest, and technology interest). A significant regression model was found $(\mathrm{F}(3,447.91=13.97, \mathrm{p}=.000)$, with an $\mathrm{R} 2$ value of .36. This indicates that interest in engineering, math, and technology explains approximately $36 \%$ of the variance in the likelihood that girls would pursue a STEM career.

Stepwise multiple regression was performed to determine the capability of STEM variables for predicting career interest for boys. Four variables surfaced as a "best model" (science interest, engineering interest and mathematics interest, and scores on the understanding of a solenoid). A significant regression model was found $(\mathrm{F}(4,400.38=16.42, \mathrm{p}=.000)$, with an $\mathrm{R} 2$ of .47 . Overall, science, engineering, mathematics interests, and understanding of a solenoid explain $47 \%$ of the variance in boys' pursuing a STEM career. The common predictors that were kept in the model for both boys and girls seeking a STEM career are their interests in engineering and math. While the results of this study showed technology as a factor in the model predictor of girls' interest in a STEM career, technology was not a factor in the model for boys pursuing STEM careers. Instead, interest in science and knowledge of a solenoid were factors in the model for boys' interest in a STEM career. Visual perception (shapes test) and TIMSS did not account for any of the variation in predicting either genders' interest in moving on to a STEM career at the middle school level.

Table 2.

Model for Predicting Career Interest for $7^{\text {th }}$ Grade Girls from STEM Related Variables

\begin{tabular}{lllcc}
\hline Model R & & R Square & R Square Change & $\begin{array}{c}\text { Sig. F } \\
\text { Change }\end{array}$ \\
\hline Engineering & .483 & .233 & .233 & .000 \\
Math & .558 & .311 & .078 & .004 \\
Technology & .599 & .358 & .047 & .002 \\
\hline
\end{tabular}

Dependent Variable: Career Interest

Table 3.

Model for Predicting Career Interest for $7^{\text {th }}$ Grade Boys from STEM Related Variables

\begin{tabular}{lcccc}
\hline Model & R & R Square & R Square Change & $\begin{array}{l}\text { Sig F } \\
\text { Change }\end{array}$ \\
\hline Science & .552 & .304 & .304 & .000 \\
Engineering & .621 & .386 & .082 & .002 \\
Math & .662 & .439 & .053 & .010 \\
Solenoid & .686 & .470 & .031 & .040 \\
\hline
\end{tabular}

These two regression analyses respond to research subquestion 2: Do the same factors predict a best fit model for 7th grade male and female students' dispositions towards a career in STEM? Stepwise regression produced a stronger model for predicting boys' interest in a STEM career $(\mathrm{R} 2=.48)$ versus girls' interest in a 
STEM career ( $\mathrm{R} 2=.358)$. The "best fit model" for predicting career interest varied between boys (science, engineering, mathematics, solenoid knowledge) and girls (engineering, mathematics, and technology interests) (See Tables 2 and 3 and Figure 2).

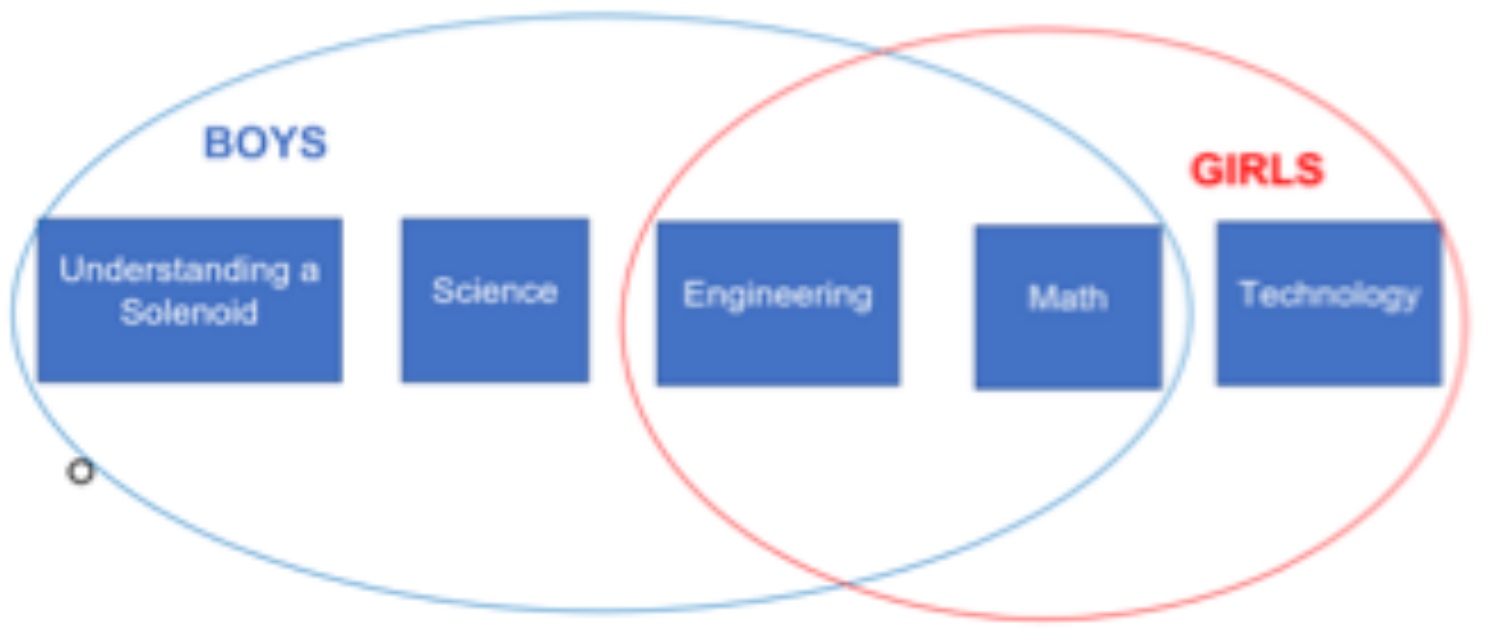

Figure 2. Interests impacting 7th grade students' preference for STEM careers according to gender

\section{Discussion and Conclusion}

The purpose of this study was to investigate factors that influence middle school students' career preferences, particularly in subject areas that create a direct pathway to STEM education and STEM jobs. Any field that attempts to predict human behavior typically has R-squared values lower than $50 \%$, since humans are harder to predict than physical processes (Frost, 2013). The predictive value of the stepwise regression for boys approached the 0.50 marker, indicating that these variables have a fairly strong potential of predicting interest in a STEM career. The findings from this study confirm existing research by providing additional evidence that, in general, males continue to strongly outnumber females in STEM career interest (Jackson, et al., 2017; Kanny et al., 2014).

Although the R-squared values for predicting a STEM career may appear low, particularly for girls, these are statistically significant predictors. Changes in the predictor values that are associated with changes in the "best fit" models produced through stepwise regression can be valuable in looking at factors that may influence STEM career choices across gender. No significant differences were found between boys' and girls' STEM variable scores except for interest in math. Historically, girls have scored lower and displayed less interest in math (Salzman, 2013; Wang \& Degol, 2017). Math interest is a significant predictor of whether girls will pursue a career in STEM. The relationship between math skills, math interest, and interest in a STEM career needs further investigation.

In our study, the ability to understand a solenoid influenced boys' interests in STEM careers more than it influenced girls' interests. Because success often leads to interest, it is likely that boys experienced more success with the abstract, application-based solenoid unit than did the girls. This supports previous findings of lower math performance among boys than girls until around sixth grade, when the instructional approach becomes more abstract and application-based (Jeng \& Liu, 2016). If, as these authors theorize, "mental rotation" tasks become "spatial visualization" tasks around this time, perhaps middle school girls' interest in STEM would increase if supported by instructional techniques that encourage deep thinking and learning success.

Results from our study found no significant difference between boys' and girls' test scores in science, technology, or engineering. In addition, there was no difference in gender scores on the career interest subtest. 
This supports previous research positing that ability levels appear to be similar for both boys and girls (Diekman et al., 2017), and indicates that both genders are potentially able to pursue STEM education and careers (Stoeger et al., 2013; Wang et al., 2015). Efforts to reduce the gender gap in STEM must extend throughout and beyond the K-16 educational settings, with educators and parents reinforcing the viewpoint that girls can be equally competitive and successful in STEM (Xu, 2016). Placing less emphasis on gender role education will create an environment that will better enable girls to openly express interest in and explore STEM education (Xu, 2016).

Applying the human constructivist learning theory as an explanation of the variation in the relationship strength of boys' and girls' interests, abilities, and performance in STEM appears warranted. Adopting an approach to teaching that is student centered, whereby students have the opportunity to actively engage in the learning process as new knowledge, ideas, and experience are constructed, will allow both boys and girls to better understand their environments (Ultanir, 2012; Yager, 1991). This approach to learning extends beyond the formalities of the classroom (Yager, 1991). Findings from an action research study (Tyler-Wood, et al., 2011) support this approach, as fourth and fifth grade girls increased in scientific awareness and confidence after engaging in outdoor hands-on science experiences.

Limitations. The limited number of participants (182 seventh grade students) and similar socioeconomic status of most students may hinder generalization of results.

Future directions. Future studies should extend the investigation to include students from other elementary and middle school grades. Analyzing specific factors through a variety of data collection methods and research designs could expand and add depth to the understanding of student career preferences. Since current study results explain only $36 \%$ and $47 \%$ of the variance of boys' and girls' interest in STEM careers, other factors clearly contribute to STEM interests. Additional factors influencing the potential for STEM education and careers should also be investigated among younger students.

The findings of this study add to the literature on the STEM gender divide and confirm that numerous challenges still exist in creating a more equal gender representation among the STEM workforce $(\mathrm{Xu}, 2016)$.

\section{References}

Aud, S., Hussar, W., Johnson, F., Kena, G., Roth, E., Manning, E., Wang., Zhang, J. (2012). The condition of education 2012. Institute of Education Sciences, U.S. Department of Education, https://nces.ed.gov/ pubs2012/2012045.pdf

Battista, M. T. (1990). Spatial visualization and gender differences in high school geometry. Journal for Research in Mathematics Education, 47-60.

Blickenstaff, J. C. (2005). Women and science careers: leaky pipeline or gender filter? Gender and Education, 17(4), 369-386.

Bretz S. L. (2001). Novak's theory of education: Human constructivism and meaningful learning. Journal of Chemistry Education, 78, 1107.

Ceci, S. J., \& Williams, W. M. (2007). Why aren't more women in science. Top researchers debate the evidence. Washington, DC: American Psychological Association.

Cheryan, S., Ziegler, S. A., Montoya, A. K., \& Jiang, L. (2017). Why are some STEM fields more gender balanced than others? Psychological Bulletin, 143(1), 1-35.

Connors-Kellgren, A., Parker, C. E., Blustein, D. L., \& Barnett, M. (2016). Innovations and Challenges in Project-Based STEM Education: Lessons from ITEST. Journal of Science Education and Technology, 25(6), 825-832.

Cross, S. E., \& Madson, L. (1997). Models of the self: self-construals and gender. Psychological bulletin, 122(1), 5. 
Crowley, K., Callanan, M. A., Tenenbaum, H. R., \& Allen, E. (2001). Parents explain more often to boys than to girls during shared scientific thinking. Psychological Science, 12(3), 258-261.

Dabney, K. P., Tai, R. H. (2014). Factors Associated with Female Chemist Doctoral Career Choice Within the Physical Sciences. J. Chem. Educ, 91(11), 1777-1786.

De Vellis, R. F., \& Dancer, L. S. (1991). Scale development: theory and applications. Journal of Educational Measurement, 31(1), 79-82.

Diekman, A. B., Steinberg, M., Brown, E. R., Belanger, A. L., \& Clark, E. K. (2017). A goal congruity model of role entry, engagement, and exit: understanding communal goal processes in STEM gender gaps. Personality and Social Psychology Review, 21(2), 142-175.

Eccles J. S. (2009). Who am I and what am I going to do with my life? Personal and collective identities as motivators of action. Educational Psychology, 44, 78-89.

Freeman C (2004). Trends in educational equity of girls \& women: 2004 (No. NCES 2005016).

Frost, J. (2013). Regression analysis: How do I Interpret R-squared and assess the goodness-of-fit? http://blog. minitab.com/blog/adventures-in-statistics/regression-analysis-how-do-i-interpret-r-squared-andassess-the-goodness-of-fit

Goan, S. K., \& Cunningham, A. F. (2006). The investment payoff: A 50-state analysis of the public and private benefits of higher education. American Academic, 2(1), 23-38.

Halpern, D. F., Benbow, C. P., Geary, D. C., Gur, R. C., Hyde, J. S., \& Gernsbacher, M. A. (2007). The science of sex differences in science and mathematics. Psychological Science in the Public Interest, 8(1), 1-51.

Hedman, L., Ström, P., Andersson, P., Kjellin, A., Wredmark, T., \& Felländer-Tsai, L. (2006). High-level visualspatial ability for novices correlates with performance in a visual-spatial complex surgical simulator task. Surgical Endoscopy and Other Interventional Techniques, 20(8), 1275-1280.

Jackson, F. L., Charleston, L. J., Lewis, C.W., Gilbert, J. E., \& Parris, W. P., (2017). Arizona's rising STEM occupational demands and declining participation in the scientific workforce: An examination of attitudes among African Americans toward STEM college majors and careers. Texas Education Review, 5(2), 91-111.

Jeng, H. L., \& Chen, Y. F. (2013). Comparisons of latent factor region means of spatial ability based on measurement invariance. Learning and Individual Differences, 27, 16-25.

Kanny, M. A., Sax, L. J., \& Riggers-Piehl, T. A. (2014). Investigating forty years of STEM research: How explanations for the gender gap have evolved over time. Journal of Women and Minorities in Science and Engineering, 20(2).

Lindberg, S. M., Hyde, J. S., Petersen, J. L., \& Linn, M. C. (2010). New trends in gender and mathematics performance: a meta-analysis.

Linn, M. C., \& Petersen, A. C. (1985). Emergence and characterization of sex differences in spatial ability: A meta-analysis. Child development, 1479-1498.

Lubinski D., \& Benbow C. P. (2006). Study of mathematically precocious youth after 35 years: uncovering antecedents for the development of math-science expertise. Perspective Psychological Science, DOI:1316-345 10.1111/j.1745-6916.2006.00019

Mau, W. C. J., Perkins, V. J., \& Mau, Y. H. (2016). Gender and Racial Differences in Career Decision-making Dispositions of College Students Enrolled in STEM Majors.

Mintzes, J. J., Wandersee, J. H., \& Novak, J. D. (Eds.). (2005). Assessing science understanding: A human constructivist view. Academic Press.

National Science Foundation. (2014). Integrated postsecondary education data system, 2013, completions survey. National Center for Science and Engineering Statistics: Integrated Science and Engineering Resources Data System (WebCASPAR). Retrieved from https://webcaspar.nsf.gov 
Novak, J. D. (1993). Human constructivism: A unification of psychological and epistemological phenomena in meaning making. International Journal of Personal Construct Psychology, 6, 167-193.

Quinn, David M., \& North Cooc. (2015). Science Achievement Gaps by Gender and Race/Ethnicity in Elementary and Middle School: Trends and Predictors. Educational Researcher, 44(6): 336-346.

Rutter, J., Standish, N., \& Bull, G. (2016, March). Using Hands-on Learning Modules to Address Challenging Concepts in Electricity and Magnetism. In Society for Information Technology \& Teacher Education International Conference(pp. 1510-1515). Association for the Advancement of Computing in Education (AACE).

Salzman, H. (2013). What shortages? The real evidence about the STEM workforce. Issues in Science and Technology, 29(4), 58-67.

Sax, L. J. (2012). Examining the underrepresentation of women in STEM fields: Early findings from the field of computer science.

Schult, J., \& Sparfeldt, J. R. (2016). Do non-g factors of cognitive ability tests align with specific academic achievements? A combined bifactor modeling approach. Intelligence, 59, 96-102.

Shumow, L., \& Schmidt, J. A. (2013). Academic Grades and Motivation in High School Science Classrooms Among Male and Female Students: Associations with Teachers' Characteristics, Beliefs and Practices. J. Education Research, 7, 53-72.

Singh, K. (2007). Quantitative Social Research Methods. SAGE Publications, Thousand Oaks, CA.

Stansell, A., \& Tyler-Wood, T. (2016, March). Reflections on Being New to Digital Fabrication. In Society for Information Technology \& Teacher Education International Conference (pp. 2357-2361). Association for the Advancement of Computing in Education (AACE).

Stoeger, H., Duan, X., Schirner, S., Greindl, T., \& Ziegler, A. (2013). The effectiveness of a one-year online mentoring program for girls in STEM. Computers \& Education, 69, 408-418.

Stumpf, H., \& Eliot, J. (1995). Gender-related differences in spatial ability and the k factor of general spatial ability in a population of academically talented students. Personality and Individual Differences, 19(1), $33-45$.

Su, R., Rounds, J., \& Armstrong, P. I. (2009). Men and things, women and people: a meta-analysis of sex differences in interests.

Tyler-Wood, T., Ellison, A., Lim, O., \& Periathiruvadi, S. (2012). Bringing up girls in science (BUGS): The effectiveness of an afterschool environmental science program for increasing female students' interest in science careers. Journal of Science Education and Technology, 21(1), 46-55.

Tyler-Wood, T., Knezek, G., \& Christensen, R. (2010). Instruments for assessing interest in STEM content and careers. Journal of Technology and Teacher Education, 18(2), 341-363.

Tyson W. (2011). Modeling engineering degree attainment using high school and college physics and calculus course taking and achievement. Journal of Engineering Education, 100, 760-777

Ultanir, E. (2012). An epistemological glance at the constructivist approach: Constructivist learning in Dewey, Piaget, and Montessori. International Journal of Instruction, 5(2), 1308-1470.

Unfried, A.; Faber, M.; Wiebe, E. Gender and Student Attitudes toward Science, Technology, Engineering, and Mathematics. The Friday Institute for Educational Innovation at North Carolina State University 2014, http://miso.ncsu.edu/wp-content/uploads/2014/08/AERA-2014-paper-Student-Attitudes-TowardSTEM.pdf

U.S. Bureau of Labor Statistics. (2015). STEM crisis or STEM surplus? Yes and yes. Accessed December 1, 2017, from https://www.bls.gov/opub/mlr/2015/article/stem-crisis-or-stem-surplus-yes-and-yes-1.htm 
U.S. Economics and Statistics Administration. (2017). STEM jobs: 2017 update. Accessed December 1, 2017, from http://www.esa.doc.gov/reports/stem-jobs-2017-update

Voyer, D., \& Voyer, S. D. (2014). Gender differences in scholastic achievement: A meta-analysis. Psychological Bulletin, 140(4), 1174.

Wang, M. T., \& Degol, J. (2013). Motivational pathways to STEM career choices: Using expectancy-value perspective to understand individual and gender differences in STEM fields. Developmental Review, 33(4), 304-340.

Wang, M. T., \& Degol, J. L. (2017). Gender gap in science, technology, engineering, and mathematics (STEM): current knowledge, implications for practice, policy, and future directions. Educational psychology review, 29(1), 119-140.

Wang, M.-T., Degol, J., \& Ye, F. (2015). Math achievement is important, but task values are critical, tool: examining the intellectual and motivational factors leading to gender disparities in STEM careers. Frontiers in Psychology, 6, 36. http://doi.org/10.3389/fpsyg.2015.00036

Weinburgh, M. (1995). Gender differences in student attitudes toward science: A meta-analysis of the literature from 1970 to 1991. Journal of Research in science Teaching, 32(4), 387-398.

$\mathrm{Xu}, \mathrm{Y}$. J. (2016). Aspirations and application for graduate education: gender differences in low-participation STEM disciplines. Research in Higher Education, 57(8), 913-942.

Yager, R. E. (1991). The constructivist learning model: Towards real reform in science education. The Science Teacher, 58(6), 52- 57

Zimmerman, E. L. (2016). 2D and 3D fabrication devices: Can they improve spatial reasoning skills in children?(Order No. 10307634). Available from Dissertations \& Theses @ University of North Texas. (1871546915). Retrieved from https://libproxy.library.unt.edu/login?url=https://libproxy.library.unt. edu:2165/docview/1871546915? accountid=7113 